\title{
IN VITRO EVALUATION OF METABOLIC DRUG-DRUG INTERACTIONS: CONCEPTS AND PRACTICE
}

\author{
Albert P. Li
}

\section{CONTENTS}

1.1 Introduction 2

1.2 Mechanisms of Adverse Drug-Drug Interactions 4

1.2.1 Pharmacological Interactions 4

1.2.2 Pharmacokinetic Interactions 5

1.3 Drug Metabolism $>5$

1.3.1 Phase I Oxidation 5

1.3.2 Phase II Conjugation 7

$\begin{array}{lll}1.4 & \text { CYP Isoforms } & 7\end{array}$

1.5 Human In Vitro Experimental Systems for Drug Metabolism 7

1.5.1 Hepatocytes $\quad 8$

1.5.2 Liver Postmitochondrial Supernatant (PMS) 9

1.5.3 Human Liver Microsomes 9

1.5.4 Recombinant P450 Isoforms (rCYP) 9

1.5.5 Cytosol 9

1.6 Mechanisms of Metabolic Drug-Drug Interactions 9

1.7 Mechanism-Based Approach for Evaluation of Drug-Drug

$\begin{array}{lll}\text { 1.7.1 Metabolic Phenotyping } & 11\end{array}$

1.7.2 Evaluation of Inhibitory Potential for Drug-Metabolizing Enzymes 11

$\begin{array}{ll}\text { 1.7.3 Induction Potential for Drug-Metabolizing Enzymes } & 11\end{array}$

1.8 Experimental Approaches for In Vitro Evaluation of Drug-Drug Interaction Potential 11

1.8.1 Study 1: Metabolic Phenotyping 1-Metabolite Identification 11

Drug-Drug Interactions in Pharmaceutical Development, Edited by Albert P. Li

Copyright (C) 2008 John Wiley \& Sons, Inc. 
1.8.2 Study 2: Metabolic Phenotyping 2-Identification of Major Metabolic Pathways

1.8.3 Study 3: Metabolic Phenotyping 3-Identification of P450 Isoform Pathways (P450 Phenotyping)

$\begin{array}{ll}\text { 1.8.4 Study 4: CYP Inhibitory Potential } & 16\end{array}$

$\begin{array}{ll}\text { 1.8.5 Study 5: Enzyme Induction Potential } & 19\end{array}$

1.8.6 Study 6: In Vitro Empirical Drug-Drug Interactions 22

1.9 Data Interpretation $\quad 22$

$\begin{array}{lll}\text { 1.9.1 Pathway Evaluation } & 22\end{array}$

$\begin{array}{lll}1.9 .2 & \text { P450 Inhibition } & 23\end{array}$

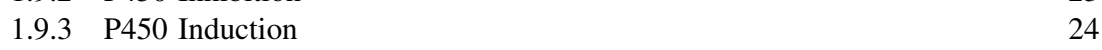

1.10 Conclusion 25

\subsection{INTRODUCTION}

Simultaneous coadministration of multiple drugs to a patient is highly probable. A patient may be coadministered multiple drugs to allow effective treatment of a disease (e.g., cancer, HIV infection) or for the treatment of multiple disease or disease symptoms. It is now known that drug-drug interactions may have serious, sometimes fatal, consequences. Serious drugdrug interactions have led to the necessity of a drug manufacturer to withdraw or limit the use of marketed drugs. Examples of fatal drug-drug interactions are shown in Table 1.1. As illustrated by the examples in Table 1.1, a major mechanism of adverse drug-drug interactions is the inhibition of the metabolism of a drug by a coadministered drug, thereby elevating the systemic burden of the affected drug to a toxic level.

Besides toxicity, loss of efficacy can also result from drug-drug interactions. In this case, the metabolic clearance of a drug is accelerated due to the inducing effects of a coadministered drug on drug metabolism. A well-known example is the occurrence of breakthrough bleeding and contraceptive failures of women taking oral contraceptives but were coadministered with the enzyme inducer rifampin (Zhang et al., 2007). Examples of drug-drug interactions leading to the loss of efficacy are shown in Table 1.2.

Estimation of drug-drug interaction potential is therefore an essential element of drug development. Screening for drug-drug interaction in early phases of drug development allows the avoidance of the development of drug candidates with high potential for adverse drug interactions. Estimation of drug-drug interaction potential is a regulatory requirement-it is required for new drug applications (NDA) to U.S. FDA (Huang et al., 1999). In this chapter, the scientific principles, technologies, and experimental approaches for the preclinical evaluation of drug-drug interactions are reviewed. 


\section{TABLE 1.1 Drugs Withdrawn from Market due to Fatal Interactions with Coadministered Drugs}

\begin{tabular}{|c|c|c|}
\hline Drug-drug interaction & Mechanism of interactions & References \\
\hline $\begin{array}{l}\text { Terfenadine/ketoconazole interaction, } \\
\text { leading to fatal arrhythmia (torsade } \\
\text { de pointes). Terfenadine has been } \\
\text { withdrawn from the market in } \\
\text { January } 1997 \text { and replaced by a safer } \\
\text { alternative drug (fexofenadine) that is } \\
\text { the active metabolite of terfenadine }\end{array}$ & $\begin{array}{l}\text { Terfenadine is metabolized mainly } \\
\text { by CYP3A4 and has been found } \\
\text { to interact with CYP3A4 } \\
\text { inhibitors (e.g., ketoconazole) } \\
\text { leading to the elevation of } \\
\text { plasma terfenadine level to } \\
\text { cardiotoxic levels }\end{array}$ & $\begin{array}{l}\text { Vazquez and Whitfield (1997); Carlson } \\
\text { and Morris (1996); Von Moltke } \\
\text { et al. (1996); www.fda.gov/bbs/topics/ } \\
\text { answers/ans00853.html }\end{array}$ \\
\hline $\begin{array}{l}\text { Mibefradil interaction with multiple drugs, } \\
\text { leading to serious adverse effects. Mibefradil } \\
\text { interactions with statins has led to } \\
\text { rhabdomyolysis. } \\
\text { Mibefradil was withdrawn from the market in } \\
\text { June 1998, less than a year after it was } \\
\text { introduced to the market in August } 1997\end{array}$ & $\begin{array}{l}\text { Mibefradil is a potent CYP3A4 } \\
\text { inhibitor known to elevate the } \\
\text { plasma levels of over } 25 \\
\text { coadministered drugs to toxic } \\
\text { levels. Statins, especially } \\
\text { simvastatin and cerivastatin, } \\
\text { are known to cause rhabdomyolysis }\end{array}$ & $\begin{array}{l}\text { Omar and Wilson (2002); www.fda.gov/ } \\
\text { bbs/topics/answers/ans00876.html }\end{array}$ \\
\hline $\begin{array}{l}\text { Sorivudine/5-fluorouracil (5-FU) interaction, } \\
\text { leading to severe or fatal gastrointestinal and } \\
\text { bone marrow toxicities. Soruvidine was } \\
\text { withdrawn from the market in } 1993\end{array}$ & $\begin{array}{l}\text { Sorivudine inhibits dihydropyrimidine } \\
\text { dehydrogenase, an enzyme pathway } \\
\text { responsible for fluoropyrimidine } \\
\text { metabolism }\end{array}$ & Diasio (1998) \\
\hline $\begin{array}{l}\text { Gemfibrozil-cerivastatin interaction, leading } \\
\text { to rhabdimyolysis. Cerivastatin was } \\
\text { withdrawn from the market in August, } 2001\end{array}$ & $\begin{array}{l}\text { Inhibition of cerivastatin metabolism by } \\
\text { gemfibrozil, apparently due to } \\
\text { CYP2C8 inhibitory effects of gemfibrozil }\end{array}$ & $\begin{array}{l}\text { Ozdemir et al. (2000); www.fda.gov/ } \\
\text { medwatch/safety/2001/ } \\
\text { Baycol2.html }\end{array}$ \\
\hline
\end{tabular}


TABLE 1.2 Drug-Drug Interactions Leading to Loss of Efficacy

\begin{tabular}{|c|c|c|}
\hline Drug-drug interaction & Mechanism & Reference \\
\hline $\begin{array}{l}\text { Oral contraceptive-rifampin } \\
\text { interactions, leading to the } \\
\text { breakthrough bleeding and } \\
\text { contraceptive failure }\end{array}$ & $\begin{array}{l}\text { Rifampin accelerates the } \\
\text { metabolism of the } \\
\text { estrogenic component } \\
\text { (e.g., } 17 \text { alpha-ethinylestradiol) } \\
\text { of oral contraceptives via } \\
\text { induction of the metabolizing } \\
\text { enzymes (CYP3A4 and } \\
\text { estrogen sulphotransferases) }\end{array}$ & $\begin{array}{l}\text { Zhang et al. (2007); } \\
\text { Li et al. (1999). }\end{array}$ \\
\hline $\begin{array}{l}\text { Cyclosporin-rifampin } \\
\text { interaction, leading } \\
\text { to rejection of } \\
\text { transplanted organs }\end{array}$ & $\begin{array}{l}\text { Rifampin induces CYP3A, } \\
\text { leading to accelerated } \\
\text { metabolic clearance of } \\
\text { cyclosporine to } \\
\text { non-immuosuppressive level }\end{array}$ & $\begin{array}{l}\text { Capone et al. } \\
\text { (1996) }\end{array}$ \\
\hline $\begin{array}{l}\text { St. John's Wort (SJW) } \\
\text { interactions with } \\
\text { prescribed drugs, } \\
\text { leading to loss } \\
\text { of efficacy }\end{array}$ & $\begin{array}{l}\text { SJW (Hypericum perforatum) } \\
\text { is a herbal medicine found } \\
\text { to contain ingredients that } \\
\text { can induce CYP3A4, } \\
\text { CYP2C9, CYP1A2, and } \\
\text { various transporters, leading } \\
\text { to clinically observed } \\
\text { accelerated metabolic } \\
\text { clearance and/or loss of } \\
\text { efficacy of a large number } \\
\text { of drugs including warfarin, } \\
\text { phenprocoumon, cyclosporine, } \\
\text { HIV protease inhibitors, } \\
\text { theophylline, digoxin, and } \\
\text { oral contraceptives. The } \\
\text { incidents with SJW illustrate } \\
\text { the importance of the evaluation } \\
\text { of potential drug-drug } \\
\text { interaction potential of } \\
\text { herbal medicines }\end{array}$ & $\begin{array}{l}\text { Henderson et al. } \\
\quad(2002)\end{array}$ \\
\hline
\end{tabular}

\subsection{MECHANISMS OF ADVERSE DRUG-DRUG INTERACTIONS}

Adverse effects in a patient due to coadministration of multiple drugs can be due to pharmacological or pharmacokinetic drug-drug interactions as defined in the following sections.

\subsubsection{Pharmacological Interactions}

Adverse effects that occur due to combined pharmacological activities lead to exaggerated pharmacological effects. An example of pharmacological 
interactions is serious, sometimes fatal drop in blood pressure due to coadministration of nitroglycerin and sedfenadil (Schalcher et al., 2002).

\subsubsection{Pharmacokinetic Interactions}

Adverse effects that occur due to altered body burden of a drug as a result of a coadministered drug can occur because of the ability of one drug to alter the absorption, distribution, metabolism, and excretion (ADME properties) of the coadministered drug. Of the ADME properties, drug metabolism represents the most important and prevalent mechanism for pharmacokinetic interactions.

\subsection{DRUG METABOLISM}

All drugs administered to a patient are subject to biotransformation. Orally administered drugs are first subjected to metabolism by the intestinal epithelium, and, upon absorption into the portal circulation, metabolized by the liver before entering the systemic circulation. While multiple tissues have certain degree of biotransformation capacity, it is generally accepted that hepatic metabolism represents the most important aspect of drug metabolism.

Drug metabolism can be classified into the following major categories.

\subsubsection{Phase I Oxidation}

This is generally described as the addition of an oxygen atom (e.g., as a hydroxyl moiety) to the parent molecule. Phase I oxidation is carried out by multiple enzyme pathways, including the various isoforms of the cytochrome P450 (CYP) family and the non-P450 biotransformation enzymes such as flavin-containing monooxygenase (FMO) and monamine oxidase (MAO).

\subsubsection{Phase II Conjugation}

Phase II conjugation represents enzyme reactions that lead to the addition of a highly water-soluble molecule to the chemical that is being metabolized, leading to highly water soluble "conjugates" to allow efficient excretion. Examples of phase II enzymes are uridine dinucleotide phosphate (UDP)glucuronyl transferase (UGT), sulfotransferase (ST), and glutathione-Stransferase (GST). Conjugation reactions often occur with the hydroxyl moiety of the parent structure or with the oxidative metabolites.

The major drug-metabolizing enzymes and subcellular locations are summarized in Table 1.3. 
a TABLE 1.3 Major Pathways for Drug Metabolism, Enzymes, Subcellular Locations, and In Vitro Experimental System Containing Enzymes

\begin{tabular}{|c|c|c|c|}
\hline Major classification & Enzyme & Subcellular location & $\begin{array}{c}\text { Representative In Vitro } \\
\text { experimental system }\end{array}$ \\
\hline \multirow[t]{5}{*}{ Phase I oxidation } & $\begin{array}{l}\text { Cytochrome P450 mixed } \\
\text { function monooxygenases }\end{array}$ & Endoplasmic reticulum & $\begin{array}{l}\text { Microsomes; S9; } \\
\text { hepatocytes }\end{array}$ \\
\hline & Monoamine oxidase & Mitochondria & Hepatocytes \\
\hline & $\begin{array}{l}\text { Flavin-containing } \\
\text { monooxygenase }\end{array}$ & Endoplasmic reticulum & $\begin{array}{l}\text { Microsomes; S9; } \\
\text { hepatocytes }\end{array}$ \\
\hline & $\begin{array}{l}\text { Alchohol/aldehyde } \\
\text { dehydrogenase }\end{array}$ & Cytosol & S9; hepatocytes \\
\hline & Esterases & $\begin{array}{l}\text { Cytosol and } \\
\text { endoplasmic reticulum }\end{array}$ & $\begin{array}{l}\text { Microsomes; S9; } \\
\text { hepatocytes }\end{array}$ \\
\hline \multirow[t]{5}{*}{ Phase II conjugation } & $\begin{array}{l}\text { UDP-glucuronyl } \\
\text { transferase }\end{array}$ & Endoplasmic reticulum & $\begin{array}{l}\text { Microsomes; S9; } \\
\text { hepatocytes }\end{array}$ \\
\hline & $\begin{array}{l}\text { Phenol sulfotransferases; } \\
\text { estrogen sulfotransferase }\end{array}$ & Cytosol & S9; hepatocytes \\
\hline & $N$-Acetyl transferase & Endoplasmic reticulum & $\begin{array}{l}\text { Microsomes; S9; } \\
\text { hepatocytes }\end{array}$ \\
\hline & $\begin{array}{l}\text { Soluble glutathione- } \\
S \text {-transferases (GST) }\end{array}$ & Cytosol & S9; hepatocytes \\
\hline & Membrane-bound GST & Endoplasmic retuculum & $\begin{array}{l}\text { Microsomes; S9; } \\
\text { hepatocytes }\end{array}$ \\
\hline
\end{tabular}

These enzymes are grouped into Phase I oxidation and Phase II conjugation enzymes, although it is now believed that such classification may not be possible for all drug-metabolizing enzymes. Representative in vitro experimental systems containing these enzymes are shown to guide the selection of the most relevant approach for specific enzyme pathways. It is apparent that intact hepatocyte represent the most complete in vitro system for drug metabolism studies as they contain all the key hepatic drug-metabolizing enzyme pathways. 
TABLE 1.4 Major Human P450 Isoforms Involved in Drug Metabolism

\begin{tabular}{llll}
\hline CYP isoform & Substrate & Inhibitor & Inducer \\
\hline CYP1A2 & Phenytoin & Furafylline & Omeprazole \\
CYP2A6 & Coumarin & Tranylcypromine & Rifampin \\
CYP2B6 & Bupropion & Ticlopidine & Rifampin \\
CYP2C8 & Taxol & Quercetin & Rifampin \\
CYP2C9 & Tolbutamide & Sulfaphenazole & Rifampin \\
CYP2C19 & s-Mephenytoin & Omeprazole & Rifampin \\
CYP2D6 & Dextromethorphan & Quinidine & None \\
CYP2E1 & Chlorzoxazone & Diethyldithiocarbamate & Ethanol \\
CYP3A4 & Testosterone & Ketoconazole & Rifampin \\
\hline
\end{tabular}

The individual isoforms and examples of isoform-specific substrates, inhibitors, and inducers are shown.

\subsection{CYP ISOFORMS}

CYP-dependent monooxygenases are the drug-metabolizing enzymes often involved in metabolic drug-drug interactions. The CYP family is represented by a large number of isoforms, with each having selectivity for certain chemical structures. The major hepatic human CYP isoforms involved in drug metabolism are CYP1A2, CYP2A6, CYP2B6, CYP2C8, CYP2C9, CYP2C19, CYP2D6, CYP2E1, and CYP3A4. Of these isoforms, the CYP3A isoforms are the most important in drug metabolism. CYP3A isoforms (CYP3A4 and CYP3A5) collectively represent the most abundant hepatic CYP isoforms (approximately 26\%), followed by CYP2C isoforms (approximately 17\%). In terms of the isoforms involved in drug metabolism, CYP3 isoforms are known to be involved in the metabolism of the most number of drugs (approximately $33 \%$ ), followed by CYP2C isoforms (approximately 25\%) (Guengerich, 2006).

P450 isoforms are known to have specific substrates, inhibitors, and inducers (Table 1.4).

\subsection{HUMAN IN VITRO EXPERIMENTAL SYSTEMS FOR DRUG METABOLISM}

Substantial species-species differences occur in drug metabolism pathways, especially for CYP isoforms. Because of the species-species differences, human in vitro hepatic experimental systems rather than nonhuman animals are viewed as the most relevant to the evaluation of xenobiotic properties, including human drug metabolism and metabolism-based drug-drug interactions ( $\mathrm{Li}$, 1997, 2001, 2004; MacGregor et al., 2001). The following are the commonly used in vitro experimental systems for the evaluation of metabolism-based drug-drug interactions. 


\subsubsection{Hepatocytes}

Hepatocytes are the parenchymal cells of the liver that are responsible for hepatic biotransformation of xenobiotics. Isolated hepatocytes represent the most physiologically relevant experimental system for drug metabolism studies as they contain all the major hepatic drug-metabolizing enzyme pathways that are not undisrupted such as cell-free fractions. Further, the drug-metabolizing enzymes and cofactors in the hepatocytes are present at physiological concentrations. Freshly isolated hepatocytes and cryopreserved hepatocytes are generally believed to represent the most complete in vitro system for the evaluation of hepatic drug metabolism (Hewitt et al., 2007).

In the past, the use of human hepatocytes has been severely limited by their availability, as studies would be performed only if human livers were available for hepatocyte isolation. Further, hepatocyte isolation from human livers is not a technology available to most drug metabolism laboratories. This limitation has been overcome in the past decade due to the advancements in the procurement of human livers for research and the commercial availability of isolated human hepatocytes. The application of human hepatocytes in drug metabolism studies is also greatly aided by the successful cryopreservation of human hepatocytes to retain drug metabolism activities (Li et al., 1999, 1999a, 1999b). Recently, the usefulness of cryopreserved human hepatocytes is further extended through the development of technologies to cryopreserve human hepatocytes to retain their ability to be cultured as attached cultures (plateable cryopreserved hepatocytes) that can be used for longer term studies such as enzyme induction studies ( $\mathrm{Li}, 2007)$. Examples of the viability and plateability of cryopreserved human hepatocytes prepared in our laboratory are shown in Table 1.5.

TABLE 1.5 Viability and Plateability (Ability of Hepatocytes to be Cultured as Monolayer Cultures) of the Various Lots of Cryopreserved Human Hepatocytes

\begin{tabular}{lcccc}
\hline Lot \# & Yield, cells/vial & Viability (trypan blue), $\%$ & Plating & Confluency, $\%$ \\
\hline HU4003 & $4.5 \times 10^{6}$ & 86 & YES & 100 \\
HU4001 & $6.0 \times 10^{6}$ & 80 & NO & 20 \\
HU4004 & $6.0 \times 10^{6}$ & 80 & NO & 30 \\
HU4000 & $7.2 \times 10^{6}$ & 93 & YES & 100 \\
HU4013 & $7.3 \times 10^{6}$ & 92 & YES & 75 \\
HU4016 & $6.2 \times 10^{6}$ & 81 & YES & 100 \\
HU4021 & $5.4 \times 10^{6}$ & 89 & YES & 70 \\
HU4022 & $5.5 \times 10^{6}$ & 91 & YES & 80 \\
HU4026 & $5.85 \times 10^{6}$ & 91 & NO & 10 \\
HU4027 & $5.9 \times 10^{6}$ & 92 & NO & 30 \\
HU4028 & $3.2 \times 10^{6}$ & 83 & YES & 50 \\
HU4023 & $2.1 \times 10^{6}$ & 89 & NO & 20 \\
HU4029 & $6.0 \times 10^{6}$ & 90 & YES & 80
\end{tabular}

Hepatocytes manufactured by APSciences Inc. in partnership with CellzDirect Inc. 


\subsubsection{Liver Postmitochondrial Supernatant (PMS)}

Liver PMS is prepared by firstly homogenizing the liver, and then centrifuging the homogenate at a speed of either $9000 \times g$ or $10,000 \times g$ to generate the supernatants S9 or S10, respectively. Liver PMS contains both cytosolic and microsomal drug-metabolizing enzymes, but lacks mitochondrial enzymes.

\subsubsection{Human Liver Microsomes}

Liver microsomes are the $100,000 \times g$ pellet for the PMS. Microsome preparation procedures in general involve the homogenization of the liver, dilution of the homogenate with approximately 4 volumes of tissue weight with a buffer (e.g., 0.1 M Tris-HCl, pH 7.4, 0.1 M KCl, 1.0 mM EDTA, 1.0 mM PMSF (Raucy and Lasker, 1991)), followed by centrifugation at $9000-14,000 \times g$ to remove nonmicrosomal membranes, and then at $100,000-138,000 \times g$ to pellet the microsomes (Nelson et al., 2001). Microsomes contain the smooth endoplasmic reticulum that is the site of the major phase I oxidation pathway, the P450 isoforms, esterases, as well as a major conjugating pathway, UGT.

\subsubsection{Recombinant P450 Isoforms (rCYP)}

These are microsomes derived from organisms transfected with genes for individual human P450 isoforms (e.g., bacteria, yeast, mammalian cells (Barnes et al., 1991; Donato et al., 2004; Friedberg et al., 1999)) and therefore contain only one specific human isoform. The major human P450 isoforms involved in drug metabolism are available commercially as rCYP. This experimental system is widely used to evaluate the drug-metabolizing activities of individual P450 isoforms (Rodrigues, 1999).

\subsubsection{Cytosol}

The supernatant after the $100,000 \times g$ centrifugation for microsome preparation is the cytosol that is practically devoid of all membrane-associated enzymes. $N$-Acetyl transferases, sulfotransferases, and dehydrogenases are examples of cytosolic enzymes. While drug-drug interaction studies are mainly studied using liver microsomes, there are cases of drug-drug interactions involving phase II pathways that can be studied using liver cytosol (Vrtic et al., 2003).

A comparison of the different in vitro experimental systems in their drugmetabolizing enzymes is shown in Table 1.6.

\subsection{MECHANISMS OF METABOLIC DRUG-DRUG INTERACTIONS}

Metabolic drug-drug interaction results from the alteration of the metabolic clearance of one drug by a coadministered drug. There are two major pathways of metabolic drug-drug interactions. 
TABLE 1.6 A Comparison of the Key In Vitro Drug-Metabolizing Experimental Systems (Liver Microsomes (Microsomes), Liver Postmitochondrial Supernatant (S9), Liver Cytosol (Cytosol), and Hepatocytes in their Contents of the Major DrugMetabolizing Enzymes

\begin{tabular}{lccccc}
\hline In vitro system & P450 & MAO & UGT & ST & GST \\
\hline Microsomes & + & - & $+{ }^{a}$ & - & $+^{b}$ \\
S9 & + & - & $+{ }^{a}$ & $+{ }^{a}$ & + \\
Cytosol & - & - & $-{ }^{a}$ & $+^{a}$ & $+{ }^{c}$ \\
Hepatocytes & + & + & + & + & + \\
\hline
\end{tabular}

Cytochrome P450 isoforms (P450); monoamine oxidase (MAO); UDP-glucuronsyl transferase (UGT); sulfotransferase (ST); and glutathione-S-transerase (GST).

${ }^{a}$ Activity of this drug metabolizing enzyme requires the addition of specific cofactors, for instance, UDP-glucuronic acid (UDPGA) for UGT activity, and $3^{\prime}$-phosphoadenosine $5^{\prime}$-phosphosulfate (PAPS) for ST activity.

${ }^{b}$ Membrane-bound GST but not the soluble GST are found in the microsomes.

${ }^{c}$ Soluble GST but not membrane-bound GST are found in the cytosol.

Inhibitory drug-drug interaction: When one drug inhibits the drugmetabolizing enzyme responsible for the metabolism of a coadministered drug, the result is a decreased metabolic clearance of the affected drug, resulting in a higher than desired systemic burden. For drugs with a narrow therapeutic index, this may lead to serious toxicological concerns. Most fatal drug-drug interactions are due to inhibitory drug-drug interactions.

Inductive drug-drug interactions: Drug-drug interactions can also be a result of the acceleration of the metabolism of a drug by a coadministered drug. Acceleration of metabolism is usually due to the induction of the gene expression, leading to higher rates of protein synthesis and therefore higher cellular content of the induced drug-metabolizing enzyme and a higher rate of metabolism of the substrates of the induced enzyme. Inductive drug-drug interactions can lead to a higher metabolic clearance of the affected drug, leading to a decrease in plasma concentration and loss of efficacy. Inductive drug-drug interactions can also lead to a higher systemic burden of metabolites, which, if toxic, may lead to safety concerns.

\subsection{MECHANISM-BASED APPROACH FOR EVALUATION OF DRUG-DRUG INTERACTION POTENTIAL}

Due to the realization that it is physically impossible to evaluate empirically the possible interaction between one drug and all marketed drugs, and that most drug-metabolizing enzyme pathways are well defined, a mechanism-based approach is used for the evaluation of drug-drug interaction potential of a new drug or drug candidate (Li, 1988, 2001, 2004), This mechanistic-based approach is now also recommended by the U.S. FDA (www.fda.gov/cber/ 
gdlns/interactstud.htm). The approach consists of the major studies described in the following sections.

\subsubsection{Metabolic Phenotyping}

Metabolic phenotyping is defined as the identification of the major pathways involved in the metabolism of the drug in question. The reasoning is that if the pathways are known, then one can estimate potential interaction of the drug in questions with known inhibitors or inducers of the pathway.

\subsubsection{Evaluation of Inhibitory Potential for Drug-Metabolizing Enzymes}

The ability of the drug in question to inhibit the activities of known pathways for drug metabolism is evaluated. If a drug is an inhibitor of a drug-metabolizing enzyme pathway, it will have the potential to cause inhibitory drug interactions with coadministered drugs that are substrates of the inhibited pathway.

\subsubsection{Induction Potential for Drug-Metabolizing Enzymes}

The ability of the drug in question to induce drug-metabolizing enzyme activities is evaluated. If the drug in question is an inducer of a specific pathway, it will have the potential to cause inductive drug interactions with coadministered drugs that are substrates of the induced pathway.

\subsection{EXPERIMENTAL APPROACHES FOR IN VITRO EVALUATION OF DRUG-DRUG INTERACTION POTENTIAL}

Because of the known species-species differences in drug metabolism, it is now believed that in vitro, human-based, experimental systems are more appropriate than nonhuman animal models for the evaluation of drug-drug interactions. In vitro positive findings are usually confirmed with in vivo clinical studies. The typical preclinical studies for drug-drug interactions (Li, 1988, 2001, 2004, www.fda.gov/cber/gdlns/interactstud.htm) are as given in the following sections.

\subsubsection{Study 1: Metabolic Phenotyping 1-Metabolite Identification}

The objective of this study is to identify the major metabolites of the drug in question. For this study, the drug in question is incubated with an appropriate in vitro metabolic system to allow the formation of metabolites ( $\mathrm{Li}, 2001,2004)$. Metabolites are then identified using analytical chemical approaches. The in vitro experimental system of choice is human hepatocytes, with high performance liquid chromatography/mass spectrometry (HPLC/MS) or tandem mass spectrometry (HPLC/MS/MS) as the most convenient analytical tool to identify the metabolites. 
The metabolites are generally identified as metabolites of phase I oxidation or phase II conjugation. If phase I oxidation is concluded as the major pathway for the oxidative metabolism of the drug, experiment 2 will be performed to evaluate which of the several oxidative pathways are involved. Phase II conjugation pathways can be generally identified by the identities of the metabolites, and subsequent experiments to further identify the pathways may not be necessary. For instance, if the metabolite is a glucuronide, UGT can be identified as the enzyme involved.

A typical experimental design is as follows:

- In vitro system: Cryopreserved human hepatocytes pooled from two donors (male and female).

- Three drug concentrations: 1,10 , and $100 \mu \mathrm{M}$.

- Hepatocyte concentration: 0.5-1.0 million hepatocytes per ml.

- Three incubation times: 1, 2, and $4 \mathrm{~h}$ (suspension culture); up to $24 \mathrm{~h}$ (attached culture).

- Incubation in 24 -well plates at $37^{\circ} \mathrm{C}$.

- Organic solvent (e.g., acetonitrile) to terminate reaction and to extract medium and intracellular metabolites.

- Stored frozen till analysis.

- Analytical chemistry: HPLC-MS/MS.

- Quantification of disappearance of parent chemical in all samples.

- Identification of metabolites from $100 \mu \mathrm{M}$ samples.

- Detection of metabolites in 1 and $10 \mu \mathrm{M}$ samples.

\subsubsection{Study 2: Metabolic Phenotyping 2-Identification of Major Metabolic Pathways}

If oxidative metabolites are found to be the major metabolites, it is necessary to evaluate which major oxidative pathways are involved in the metabolism. This is performed via the use of liver microsomes and experimental conditions that would inhibit a specific pathway. The major pathways and experimental conditions are shown in Table 1.7.

As P450 pathways are considered the most important for metabolic drug-drug interactions, the study with the general P450 inhibitor, 1-aminobenzotriazole (ABT), is the one that should be performed. ABT is known to inhibit all eight human P450 isoforms involved in drug metabolism (Emoto et al., 2003). Inhibition of metabolism of a test article by ABT would indicate that the test article is metabolized by the P450 pathway. A typical study with ABT is as follows:

- Human liver microsomes $(0.5 \mathrm{mg}$ protein $/ \mathrm{ml})$.

- Experiment 1: Evaluation of experimental conditions for the accurate quantification of metabolic clearance. 
TABLE 1.7 Experimental Conditions to Reduce the Activity of the Major DrugMetabolizing Enzyme Pathways [P450 Isoforms (CYP); Flavin-Containing Monooxygenases (FMO), Monoamine Oxidase (MAO)] Using In Vitro Experimental Systems for Drug Metabolism [Liver (Microsomes), Postmitochondrial Supernatant (S9), and Hepatocytes]

\begin{tabular}{lll}
\hline In vitro system & \multicolumn{1}{c}{ Condition } & Inactivated pathway(s) \\
\hline Microsomes & NADH omission & CYP, FMO \\
Microsomes or hepatocytes & 1-Aminobenzotriazole treatment & CYP \\
Microsomes & Heat $\left(45^{\circ} \mathrm{C}\right)$ inactivation & FMO \\
S9 & Pargyline treatment & MAO \\
\hline
\end{tabular}

Adapted from http://www.fda.gov/cder/guidance/6695dft.pdf.

- Incubation with three concentrations of test article (e.g., 0.1, 1, and $10 \mu \mathrm{M}$ ) and three incubation times (e.g., 15, 30, and $60 \mathrm{~min}$ ).

- Quantification of test article disappearance.

- Experiment 2: Reaction phenotyping.

- Incubation with one concentration of the test article at one incubation time (chosen from Exp. 1) in the presence and absence of three concentrations of ABT $(100,200$, and $500 \mu \mathrm{M})$.

- Quantification of test article disappearance and evaluate the effects of ABT treatment.

\subsubsection{Study 3: Metabolic Phenotyping 3-Identification of P450 Isoform Pathways (P450 Phenotyping)}

If $\mathrm{ABT}$ is found to inhibit the metabolism of the drug or drug candidate in study 2, P450 metabolism ascertained. The next step is to identify which P450 isoforms are involved in the metabolism, a process termed P450 phenotyping (Rodrigues, 1999). There are three major approaches for this study.

1.8.3.1 Liver Microsome and Isoform-Selective Inhibitors In this experiment, the test article is incubated with human liver microsomes in the presence and absence of individual selective inhibitors for the eight major CYP isoforms. The ability of an inhibitor to inhibit metabolism of the test article would indicate that the pathway inhibited by the inhibitor is involved in metabolism. For instance, if ketoconazole, a potent CYP3A4 inhibitor, is found to inhibit the metabolism of the test article, then CYP3A4 is concluded to be involved in the metabolism of the test article. It is also a common practice to assign the degree of involvement by the maximum percent inhibition. For instance, if the maximum inhibition, expressed as percentages of the total metabolism in the absence of inhibitor, by sulfaphenazole (CYP2C9 inhibitor) and ketoconazole 
(CYP3A4 inhibitor) are $20 \%$ and $80 \%$, respectively, it can be concluded that the CYP2C9 is involved in $20 \%$ and CYP3A4 in $80 \%$ of the metabolism of the test article. It is important to realize that the inhibitors are isoform-selective rather than isoform-specific, so data interpretation must be performed carefully to avoid an inaccurate assignment of enzyme pathways (Lu et al., 2003). It is always prudent to confirm the results with this study with results using a different approach (e.g., using rCYP).

1.8.3.2 Incubation with Individual rCYPs In this experiment, individual rCYPs are used to evaluate which $\mathrm{P} 450$ isoforms are involved in the metabolism (Rodrigues, 1999). The test article is incubated with each rCYP and its disappearance quantified. A rCYP that would lead to disappearance of the test article would indicate that the isoform is involved in the metabolism of the test article. For instance, if rCYP2C19 incubation leads to the disappearance of the test article, then CYP2C19 is concluded to be involved in the metabolic clearance of the test article. It is important to realize that these studies are performed with a single P450 isoform and therefore lacking competing enzyme pathways. Metabolism by a rCYP isoform may not be relevant in vivo because of higher affinity pathways.

1.8.3.3 Correlation Study with Human Liver Microsomes In this experiment, the test article is incubated with multiple lots of human liver microsomes that have been previously characterized for the activities of the individual CYPs (Ring et al., 2002). The rate of metabolic clearance of the test article is then plotted against the CYP activities of the different lots of microsomes. A linear correlation between activity and rate of disappearance for a specific CYP would indicate that this pathway is involved in the metabolism of the test article. This study requires the evaluation of at least 10 liver microsome lots with well-distributed gradations of activities.

1.8.3.4 Liver Microsome/Inhibitor Study Design In general, studies with liver microsomes are believed to be more relevant than that with $\mathrm{rCYP}$, as studies with individual rCYP does not allow competition in metabolism for isoforms with different affinities for the substrate, and therefore may overemphasize the participation of low affinity pathways. It is important to use substrate concentrations similar to expected plasma concentrations. An artifactually high concentration would cause the substrate to be metabolized similarly by high and low affinity enzyme pathways (Renwick et al., 2004). Using liver microsomes with physiologically relevant substrate concentrations should provide the best results. A typical liver microsome experiment with inhibitors is as follows:

- Human liver microsomes $(0.5 \mathrm{mg} / \mathrm{ml})$.

- Experiment 1: Metabolic stability study. 
- Incubation with three concentrations of test article (e.g., 0.1, 1, and $10 \mu \mathrm{M}$ ) and three incubation times (e.g., 15, 30, and $60 \mathrm{~min}$ ).

- Quantification of test article disappearance.

- Experiment 2: Reaction phenotyping.

- Incubation with one concentration of the test article at one incubation time (chosen from experiment 1) in the presence and absence of isoform-specific inhibitors.

- Quantification of test article disappearance.

The isoform-specific inhibitors suggested by U.S. FDA are shown in Table 1.8 .

1.8.3.5 Evaluation of CYP Isoform Contributions Using Both Liver Microsomes and $r$ CYPs It is also possible to calculate the relative contribution of individual isoforms using data from both liver microsomes and rCYPs using the following approach (Crespi, 1995; Uttamsingh et al., 2005):

First, the relative activity factor for individual isoforms (using isoformspecific substrates) is calculated. This is necessary as each lot of liver microsome would have different relative amounts of each P450 isoform. $V_{\max }$ and $K_{\mathrm{m}}$ values are determined for each isoform using isoform-specific substrates for both liver microsomes and rCYP. The relative activity factor (RAF) is calculated using the following equation:

$$
\mathrm{RAF}=V_{\max } / K_{\mathrm{m}} \text { of CYP in microsomes } / V_{\max } / K_{\mathrm{m}} \text { of } \mathrm{rCYP}
$$

TABLE 1.8 Preferred and Acceptable P450 Isoform-Specific Inhibitors Suggested by U.S. FDA in the September 2006 Draft Guidance Document for Drug-Drug Interaction Evaluation and Preferred Inhibitors used in In Vitro ADMET Laboratories (IVAL)

\begin{tabular}{|c|c|c|c|}
\hline CYP & $\begin{array}{l}\text { FDA preferred } \\
\text { inhibitor }\end{array}$ & FDA acceptable inhibitor & $\begin{array}{l}\text { IVAL preferred } \\
\text { inhibitor }\end{array}$ \\
\hline $1 \mathrm{~A} 2$ & Furafylline & alpha-Napthoflavone & Furafylline \\
\hline $2 \mathrm{~A} 6$ & $\begin{array}{l}\text { Tranylcypromine, } \\
\text { methoxsalen }\end{array}$ & Pilocarpine, tryptamine & Tranylcypromine \\
\hline 2B6 & & Ticlopidine, sertraline & Ticlopidine \\
\hline $2 \mathrm{C} 8$ & Quercetin & $\begin{array}{l}\text { Trimethorprim, gemfibrozil, } \\
\text { rosiglitazone }\end{array}$ & Quercetin \\
\hline $2 \mathrm{C} 9$ & Sulfaphenazole & Fluconazole & Sulfaphenazole \\
\hline $2 \mathrm{C} 19$ & & Ticlopidine & Omeprazole \\
\hline 2D6 & Quinidine & & Quinidine \\
\hline $2 \mathrm{E} 1$ & & Diethyldithiocarbamate & Diethyldithiocarbamate \\
\hline $3 \mathrm{~A} 4 / 5$ & $\begin{array}{r}\text { Ketoconazole, } \\
\text { itraconazole }\end{array}$ & Troleandomycin, verapamil & Ketoconazole \\
\hline
\end{tabular}


Contribution of a specific CYP isoform to metabolism of a test article is then calculated using the following equation:

$$
\text { Contribution of } \mathrm{CYP}(\%)=\mathrm{RAF} \times V(\mathrm{rCYP}) / V(\text { microsomes })
$$

\subsubsection{Study 4: CYP Inhibitory Potential}

The objective of this study is to evaluate if the drug or drug candidate in question is an inhibitor of a specific P450 isoform. This study can be performed with rCYP, human liver microsomes, and human hepatocytes.

1.8.4.1 rCYP Studies rCYP studies represent the most convenient and rapid study for the evaluation of CYP inhibitory potential. As the study involves substrates that form metabolites that can be quantified by fluorescence, the laborious and time-consuming HPLC or LC/MS sample analysis is not required. For this reason, most drug development laboratories would perform rCYP inhibition assays as a screen for P450 inhibitory potential of their drug candidates. The study involves the incubation of individual rCYP isoforms with the test article at various concentrations (e.g., seven concentrations plus solvent control) in triplicate, and a substrate that can be metabolized by the specific isoform. As the reaction contains only one single isoform, isoformspecific substrates are not required to be used. The requirement is that the substrate would generate metabolites that can be measured by a plate reader with the capability to quantify florescence.

1.8.4.2 Liver Microsome Studies Liver microsomes represent the most appropriate experimental system for the evaluation of the interaction of a drug with P450 isoforms. For the evaluation of CYP inhibitory potential, the test article is incubated with liver microsomes in the presence of individual isoform-specific substrates. The isoform-specific substrates and the metabolites quantified are shown in Table 1.9.

\section{TABLE 1.9 P450 Isoform-Specific Substrates and Their Metabolites}

\begin{tabular}{lll}
\hline CYP & \multicolumn{1}{c}{ Substrate } & \multicolumn{1}{c}{ Metabolite } \\
\hline 1A2 & Phenacetin & Acetaminophen \\
2A6 & Coumarin & 7-OH-coumarin \\
2B6 & Bupropion & Hydroxypropion \\
2C8 & Taxol & 6-Alpha-hydroxypaclitaxel \\
2C9 & Tolbutamide & 4'-Hydroxytolbutamide \\
2C19 & $s$-Mephenytoin & 4-Hydroxymephenytoin \\
2D6 & Dextromethorphan & Dextrophan \\
2E1 & Chlorzoxazone & 6-Hydroxychlorzoxazone \\
3A4/5 & Testosterone & 6-Beta-hydroxytestosterone \\
\hline
\end{tabular}

These substrates are used for the evaluation using in vitro experimental systems such as liver microsomes, liver S9, or hepatocytes in which multiple isoforms are expressed. 
1.8.4.3 Human Hepatocyte Studies rCYP and human liver microsomes are cell-free systems, allowing direct interaction of the test article with the P450 isoforms. In vivo, the inhibitor is initially absorbed into the systemic circulation and then interacts with the enzymes after penetration through the hepatocyte plasma membrane. Once inside the cytoplasm, the inhibitor may be metabolized by phase I and/or phase II metabolism and/or actively transported out of the hepatocytes, for instance, via bile excretion. Furthermore, there may be transporters present to actively uptake the inhibitor. The result is that the intracellular concentration of the inhibitor may be substantially different from the plasma concentration. Results with rCYP and human liver microsomes may not be useful to estimate in vivo inhibitory effects based on plasma concentrations if the intracellular concentration of the inhibitor is not known.

The use of intact human hepatocytes may allow a more accurate extrapolation of in vitro results to in vivo. The study is performed using intact human hepatocytes incubated with isoform-specific substrate and the test article. The intact plasma membrane and the presence of all hepatic metabolic pathways and cofactors allow distribution and metabolism of the test article. The resulting inhibitory effect therefore should be physiologically more relevant to the in vivo situation than results with cell-free systems.

It is recommended that inhibition studies with intact hepatocytes be performed if inhibitory effects of a drug or drug candidate have been observed with rCYP or liver microsomes to allow a more accurate prediction of the extent of in vivo inhibitory effects. Time-dependent inhibition of P450 can also be studied using intact human hepatocytes (McGinnity et al., 2006). One precaution with the use of intact hepatocytes is to concurrently measure also cytotoxicity. As dead hepatocytes are not active in drug metabolism, without cytotoxicity information, cytotoxic drug concentrations could be interpreted as inhibitory concentrations.

A recent advancement is to use intact hepatocytes suspended in whole human plasma for inhibition studies to allow correction for plasma protein binding ( $\mathrm{Lu}$ et al., 2007). As drugs in vivo are always in contact with $100 \%$ human blood, this is conceptually sound and therefore deserve further investigation on its general applicability. One disturbing finding in our laboratory is that testosterone, a compound that is readily metabolized in vivo, is not metabolized by intact human hepatocytes in whole plasma ( $\mathrm{Li}$, unpublished).

1.8.4.4 I $\boldsymbol{C}_{50}, K_{\boldsymbol{i}}, K_{\text {inact }}$ and $[\boldsymbol{I}] / K_{\boldsymbol{i}}$ Determinations $\quad$ Enzyme inhibition data are often presented as $\mathrm{IC}_{50}$, the concentration of the inhibitor to cause $50 \%$ inhibition at one chosen substrate concentration; $K_{\mathrm{i}}$, the inhibition constant (dissociation constant from the inhibitor-enzyme complex) determined by enzyme kinetic analysis (e.g., Dixon plot); and $K_{\text {inact, }}$ the time-dependent inhibition constant for mechanism-based inhibitors. IC $_{50}$ values can be estimated from the study described earlier. A positive inhibition, defined as dose-dependent inhibition, with the inhibited activity lower than $50 \%$ of that of the negative control, will require further experimentation to define $K_{\mathrm{i}}$ for a 
better evaluation of in vivo inhibitory potential. Further, study to determine $K_{\text {inact }}$ may be performed to evaluate if the inhibitor acts via covalent binding to the active site of the enzyme, leading to time-dependent irreversible inhibition.

$\mathrm{IC}_{50}$ is generally determined by plotting the $\log$ of the relative activity (activity in the presence of the inhibitor as a percent of the activity of the negative control (solvent control)), and then estimate the concentration yielding 50\% relative activity using linear regression analysis. $\mathrm{IC}_{50}$ can also be calculated from the relationship between inhibitor concentrations and percent of control activity with the aid of a nonlinear regression program such as SCIENTIST (Micromath, Salt Lake City, UT) (Chiba et al., 2001).

$K_{\mathrm{i}}$ can be determined using Dixon plot with the reciprocal of the activity as the $y$-axis, and inhibitor concentration as the $x$-axis. Results with at least two substrate concentrations below $V_{\max }$ are plotted, with $K_{\mathrm{i}}$ calculated as the negative of the $x$-intercept (Kim et al., 2001). $K_{\mathrm{i}}$ can also be estimated with the aid of nonlinear regression analysis software such as SYSTAT (SPPS, Inc., Chicago, IL) (Wen et al., 2001).

Most P450 inhibitors act via reversible (competitive or noncompetitive mechanisms) with which their inhibitory potential can be estimated from their $\mathrm{IC}_{50}$ or $K_{\mathrm{i}}$ values. Some inhibitors are "mechanism-based" or "time-dependent" inhibitors that can cause irreversible inhibition due to the formation of reactive metabolites by the CYP isoform, leading to covalent binding to the active site and thereby causing irreversible inhibition of the affected enzyme molecule (Walsh, 1984). Irreversible inhibitors therefore will have prolonged inhibition of the enzyme even after clearance of the drug in question. $K_{\text {inact }}$ is a measurement of the potency of such "mechanism-based" inhibitors.

$K_{\text {inact }}$ can be determined using the following approach (Madeira et al, 2004):

1. Plot the relative activity (activity in the presence of the inhibitor as a percent of the activity of the solvent or negative control) versus time and determine the slope at each inhibitor concentration;

2. Plot 1 /slope versus 1 /inhibitor concentration (Kitz-Wilson plot). $K_{\text {inact }}$ is calculated as the reciprocal of the $y$-intercept, and $K_{\mathrm{i}}$ as the negative of the reciprocal of the $x$-intercept.

$[\mathrm{I}] / K_{\mathrm{i}}$, the ratio of the anticipated or known steady state plasma drug concentration to $K_{\mathrm{i}}$, is generally used to determine the likelihood of clinical drug-drug interactions (Brown et al., 2006; Kato et al., 2003). A general rule of thumb suggested by U.S. FDA (http://www.fda.gov/cder/guidance/ 6695dft.pdf) is as follows:

- $[\mathrm{I}] / K_{\mathrm{i}}<0.1$ : Unlikely to cause in vivo drug-drug interactions.

- $[\mathrm{I}] K_{\mathrm{i}}=1$ : Possible to cause in vivo drug-drug interactions.

- $[\mathrm{I}] / K_{\mathrm{i}}>1$ : Likely to cause in vivo drug-drug interactions. 
$K_{\mathrm{i}}$ is estimated by an experiment with varying inhibitor and substrate concentrations. A typical $K_{\mathrm{i}}$ study is as follows:

- In vitro experimental system: rCYP, human liver microsomes, or hepatocytes.

- Inhibitor concentration: 5 (ideally yielding 10-90\% inhibition of activity).

- Substrate concentration: Minimum of 2 for the Dixon plot. 3 is recommended.

- Time point: 1 (within the linear time course) if time course is known, multiple (e.g., 5, 10, and $15 \mathrm{~min}$ ) if time course under the experimental conditions has not been established.

- $K_{\mathrm{i}}$ is determined by Dixon plot, plotting the reciprocal of activity versus inhibitor concentration. The negative of the $X$-coordinate value corresponding to the intercept of the plots for the low and high substrate concentrations is the $K_{\mathrm{i}}$.

For mechanism-based inhibitors, $K_{\text {inact }}$ is estimated by an experiment with varying inhibitor concentration and preincubation time. A typical $K_{\text {inact }}$ study is as follows:

- In vitro experimental system: rCYP; human liver microsomes, or hepatocytes.

- Preincubation time (preincubation of enzyme with inhibitor): 5 (e.g., 5, 10, 15, 20, and $30 \mathrm{~min}$ ).

- Inhibitor concentration: 5 (ideally yielding 10-90\% inhibition of activity).

- Substrate concentration: 1 .

- Substrate incubation time: 1 (within the linear time course) if time course is known, multiple (e.g., 5, 10, and $15 \mathrm{~min}$ ) if time course under the experimental conditions has not been established.

- $K_{\text {inact }}$ is determined by the following approach:

- Plot activity as a percent of the solvent control versus time.

- Estimate the first-order inactivation constants at each inhibitor concentration by multiplying the slope of the linear regression analysis by 2.303 .

- Determine $t_{1 / 2}$ of the inactivation reaction as $0.693 / k$.

- Plot the Kitz-Wilson plot of $t_{1 / 2}$ versus the reciprocal of the inhibitor concentration and estimate $K_{\text {inact }}$ as the $y$-intercept, and $K_{\mathrm{i}}$ as the reciprocal of the $x$-intercept.

\subsubsection{Study 5: Enzyme Induction Potential}

Enzyme induction is a major mechanism for drug-drug interactions. Induction of a drug-metabolizing enzyme by one drug would lead to the 
TABLE 1.10 Clinically Demonstrated Human Enzyme Inducers, In Vitro Induction Results in Association with Severe Hepatotoxicity

\begin{tabular}{lcc}
\hline $\begin{array}{l}\text { In vivo enzyme } \\
\text { inducer }\end{array}$ & $\begin{array}{c}\text { In vitro human } \\
\text { hepatocyte induction finding }\end{array}$ & $\begin{array}{c}\text { Severe clinical } \\
\text { hepatotoxicity }\end{array}$ \\
\hline Carbamazepine & + & + \\
Dexamethasone & + & - \\
Isoniazid & + & + \\
Omeprazole & + & + \\
Phenobarbital & + & + \\
Phenytoin & + & + \\
Rifampin & + & + \\
Rifapentine & + & - \\
Rifabutin & + & + \\
Troglitazone & + & + \\
St. John's Wort & + & + \\
\hline
\end{tabular}

enhanced metabolism of coadministered drugs that are substrates of the induced enzyme.

Experimental evaluation of enzyme induction involves the treatment of human hepatocytes for several days with the test article followed by evaluation of enzyme activities using P450 isoform-specific substrates (Li et al., 1995, 1997). As freshly isolated hepatocytes possess endogenous activities that may be the result of inducers present in the donor's systemic circulation, the isolated hepatocytes are cultured for 2-3 days to allow the P450 enzyme activities to return to a basal level. Testing for induction potential is that initiated by treatment of the cultured hepatocytes for 2-3 days to allow full expression of the induced enzyme. Induction is generally evaluated by measuring enzyme activity as activity represents the most relevant end point for drug-drug interaction. Both freshly isolated and plateable cryopreserved human hepatocytes can be used for the induction study (Li, 2007; Roymans et al., 2004, 2005).

As of this writing, all known inducers of $\mathrm{P} 450$ isoforms in vivo are inducers in vitro ( $\mathrm{Li}, 2007)$. The known human $\mathrm{P} 450$ inducers are shown in Table 1.10.

The typical experimental procedures for an enzyme induction study are as follows:

- Day 0: Plate human hepatocytes (freshly isolated or plateable cryopreserved human hepatocytes).

- Day 1: Refresh medium.

- Day 2: Refresh medium.

- Day 3: Change medium to that containing test article, solvent control, or positive controls.

- Minimum of three test article concentrations, with the high concentration at least one order of magnitude greater than expected plasma concentration. 
- If plasma concentration is not known, evaluate concentrations ranging over at least two orders of magnitude (e.g., 1, 10, and $100 \mu \mathrm{M}$ ).

- Day 4: Refresh treatment medium.

- Day 5: Refresh treatment medium.

- Day 6: Measure activity (in situ incubation with isoform-specific substrates).

The isoform-specific substrates described earlier for CYP inhibition studies are generally used for enzyme induction studies.

The known CYP inducers are now known to induce either CYP1A and/or CYP3A, with inducers of other inducible isoforms such as CYP2A6, CYP2C9, CYP2C19, and also found to be CYP3A inducers. For general enzyme induction evaluation for drug-drug interaction evaluation, it may be adequate to simply screen for CYP1A and CYP3A inductions. If CYP3A induction is observed, then investigations into CYP2A6, CYP2C9, and CYP2C19 induction are warranted.

The two most common confounding factors for P450 induction studies are as follows:

1. Inducers that are also inhibitors: The co-occurrence of $\mathrm{P} 450$ inhibition and induction (i.e., the compound is both an inhibitor and inducer) can confound induction results. Ritonavir is an example of a CYP3A4 inducer (Hariparsad et al., 2004), which is also a potent CYP3A4 inhibitor (Lillibridge et al., 1988). The inhibitory effects can overcome any induction effects using activity as an end point. For the evaluation of enzyme induction potential of inhibitors, Western blotting for the amount of enzyme proteins would be most appropriate. Studies with mRNA expression would provide data to distinguish between induction of gene expression and protein stabilization as mechanisms. As in the case of ritonavir, induction effects persist after the clearance of the drug from the systemic circulation, leading to enhanced clearance of drugs that are substrates of the induced pathways. It is important to define the induction potential of a drug even if it is found to be an enzyme inhibitor.

2. Cytotoxic compounds: Induction effects can be masked by the decrease of cell viability, as most induction assay quantify substrate metabolism in situ (in the same cell culture plate that the cells are cultured) and assume that there is no change in cell number. Cytotoxicity evaluation therefore should always be performed concurrently with induction studies. In the presence of cytotoxicity, activity should be corrected by the viability for comparison with negative control activity to assess induction potential.

A compound is concluded to be an inducer if reproducible, statistically significant, and dose-dependent induction effects are observed. U.S. FDA 
recommends the use of the criterion of " $40 \%$ of higher of the activity of positive controls" as a positive response (www.fda.gov/cber/gdlns/interactstud.htm).

\subsubsection{Study 6: In Vitro Empirical Drug-Drug Interactions}

The physiological significance of the findings based on the mechanistic approach may be substantiated by in vitro drug-drug interactions between frequently coadministered drugs that are likely to have interaction with the drug in question ( $\mathrm{Li}, 1988$ ). This is particularly important if the drug in question is either a CYP3A4 substrate or a CYP3A4 inhibitor. As CYP3A4 is now known to have different affinities for different substrates and inhibitors (Wang et al., 2000), the interaction potential for a drug and a particular coadministered drug may be substantially different from that estimated by using a surrogate substrate of CYP3A4.

This study can be performed with liver microsomes or hepatocytes. The use of hepatocytes probably would allow the development of data more relevant to humans in vivo.

\subsection{DATA INTERPRETATION}

The studies described above allow one to develop data for the estimation of drug-drug interaction potential of the drug or drug candidate in question. Accurate prediction of in vivo effects is possible only through thorough and scientifically sound interpretation of the data. While every novel chemical structure will provide unique set of data and therefore requires individualized data interpretation and/or further experimentation, the following guidelines can be use to aid the evaluation of the data generated.

\subsubsection{Pathway Evaluation}

The following are the possible outcome of the study:

1. The test article is not metabolized by liver microsomes or hepatocytes: This is indicated by the lack of metabolite formation or parent disappearance in studies 1 and 2. Hepatic metabolism is not involved in the metabolic clearance of the compound. There should be no concern with coadministered drugs that can alter hepatic drug-metabolizing enzyme activities.

2. The test article is metabolized but not metabolized by P450 isoforms: As P450-related drug-drug interactions are the most prevalent, non-P450 drug-drug interactions should be considered on a case-by-case basis. For instance, MAO interaction may be important if the drug in question may be coadministered with known MAO substrates or inhibitors. UGT substrates, for instance, may have drug interactions with UGT inhibitory drugs such as probenacid. 
3. The test article is metabolized by a single P450 isoform: This represents the easiest data to interpret, albeit not a good scenario for a drug candidate. A drug that is metabolized predominantly by a single P450 isoform will very likely to have drug-drug interactions with inhibitors of the isoform. The known cases of serious drug-drug interactions often involve a single P450 pathway, with CYP3A4 being the most prominent. Drugs that have been withdrawn due to fatal drug-drug interactions are often CYP3A4 substrates or potent CYP3A4 inhibitors. Because of the role of CYP2C8 in the metabolism of statins that are widely prescribed to combat hypercholesterolemia, CYP2C8 has become a second most important isoform for drug-drug interactions. Cerivastatin, a CYP2C8 substrate, was withdrawn from the market in August 2001 after reports of fatal interactions with the CYP2C8 inhibitor gemfibrozil (Backman et al., 2002).

4. The test article is metabolized by multiple P450 isoforms: This is generally interpreted that the test article may not have serious interactions with a specific inhibitor of one of the P450 isoforms, as the metabolic clearance can be carried out by the unaffected pathways. However, there are examples of drugs that have been found to be metabolized by multiple pathways but would later found in clinical or postmarketing studies to have interactions with potent inhibitors of a specific pathway. An example is the antifungal terbinafine that has been characterized using human liver microsomes and rCYPs to be metabolized by multiple P450 isoforms: CYP1A2, CYP2C8, CYP2C9. CYP2C19, CYP2D6, and CYP3A4, leading to the authors conclusion that "the potential for terbinafine interaction with other drugs is predicted to be insignificant" (Vickers et al., 1999). In the same study, as terbinafine was a competitive inhibitor of CYP2D6, it was concluded that it would have interactions with CYP2D6 substrates. In vivo studies confirmed the CYP2D6 inhibitory effects as predicted by in vitro studies; however, it was also observed clinically that rifampin, a CYP3A4 inducer, caused a 100\% increase terbinafine clearance (www.fda.gov/medwatch/safety/2004/ jan_PI/Lamasil_PI.pdf). One possible explanation of this is upon CYP3A4 induction, the total metabolism of terbinafine is greatly enhanced due to the high capacity of CYP3A4 for this substrate. It is therefore important to realize that if a drug is metabolized by multiple isoforms, it may still have significant drug interactions with inducers of isoforms with high capacity for the metabolism of the drug.

\subsubsection{P450 Inhibition}

The outcomes of P450 inhibition studies may include the following:

1. No inhibition observed: If no inhibitory effects are observed with rCYP, microsomes and hepatocytes, the substance in question is considered not 
to have the potential to cause inhibitory metabolic drug-drug interactions in vivo. As of now, there are no examples of in vivo enzyme inhibitors that are not inhibitors in vitro.

2. Significant inhibition observed: A practical definition of significant inhibition is that the test article is found to cause dose-dependent and $>50 \%$ inhibition of one or more P450 isoforms at the concentrations evaluated. The conclusion is that the test article is a potent inhibitor. As described earlier, the physiological significance is determined by the $[\mathrm{I}] / K_{\mathrm{i}}$ value, with any $[\mathrm{I}] / K_{\mathrm{i}}$ value of 0.1 or higher as possible or likely to cause in vivo drug-drug interactions. It is recommended that $[\mathrm{I}] / K_{\mathrm{i}}$ values obtained from cell-free systems (microsomes and rCYP) are confirmed by that with intact hepatocytes to aid an accurate prediction of in vivo effects. If the results with hepatocytes are also determined to be significant, in vivo studies will need to be performed to estimate human in vivo drug-drug interaction potential.

3. No time-dependent inhibition observed: The inhibitor is not a mechanismbased inhibitor.

4. Time-dependent inhibition observed: The inhibitor is a time-dependent inhibitor. In vivo studies will need to be performed to further define its drug-drug interaction potential.

5. Additional safety concern: A time-dependent inhibitor may need to be further studied to define its hepatotoxic potential, as a number of time-dependent P450 inhibitors are found to cause idiosyncratic hepatotoxicity.

\subsubsection{P450 Induction}

The following outcome may be observed:

1. No induction observed: The substance evaluated is not an enzyme inducer if P450 inhibitory and cytotoxic potential are eliminated as confounding factors.

2. Induction observed: The substance evaluated is observed to cause dosedependent and physiologically significant induction (e.g., induced activity over twofold of negative control activity). In the doses found to be positive are within clinical plasma concentrations (e.g., within $10 \times$ of plasma $C_{\max }$ ), in vivo studies may be needed to further define the test article's in vivo enzyme induction and the subsequent drug-drug interaction potential.

3. Additional safety concern: Enzyme inducers may need to be further evaluated for their hepatotoxic potential, as a large number of enzymeinducing drugs are found to cause severe hepatotoxicity. 


\subsection{CONCLUSION}

Drug-drug interactions can have serious, adverse consequences and therefore should be evaluated accurately before a new drug is introduced to the human populations. Due to the scientific advances in the understanding of the key human drug-metabolizing pathways, and the availability of human in vitro systems for drug-metabolism studies, human drug-drug interaction evaluations, especially drug metabolism related interactions, can be performed rapidly and efficiently. A scientific, mechanism-based approach to evaluate drug-drug interactions remains the most appropriate approach:

1. Via the understanding of the major drug-metabolizing pathways in the metabolism of the drug or drug candidate in question to assess its potential interactions with existing drugs that are inhibitors or inducers of the pathways involved.

2. A careful and exhaustive evaluation of the inhibitory potential of the drug or drug candidate in question toward the major human drugmetabolizing enzymes will allow the assessment of its potential to cause interactions with existing drugs that are substrates of the inhibited enzymes.

3. Evaluation of induction potential of the drug or drug candidate in question for the inducible human drug-metabolizing enzymes will allow the assessment of potential interactions with drugs that are substrates of the induced enzymes.

This approach is currently mainly applied toward P450 isoforms and can also be applied to non-P450 drug-metabolizing enzyme pathways. The next wave of major advances in drug-drug interactions is anticipated to be approaches for the evaluation of the interactions between drugs and drug transporters.

The success achieved with the scientific-based approaches in the evaluation of drug-drug interactions is a result of the extensive scientific research in the identification and characterization of drug-metabolizing enzymes, the definition of the mechanisms of metabolic-based drug-drug interactions, and the development, characterization, and intelligent application of the human-based in vitro experimental models for drug metabolism. Similar approaches should be adopted for the evaluation of other major adverse drug effects (e.g., idiosyncratic drug toxicity) that so far have eluded the routinely drug safety evaluation approaches. It is through an open mind-a willingness to venture toward the development of hypothesis, the testing of the hypothesis, and the development and adoption of approaches to investigate a problem based on the best science-that the field of drug safety evaluation can move forward. 


\section{REFERENCES}

Backman JT, Kyrklund C, Neuvonen M, Neuvonen PJ. Gemfibrozil greatly increases plasma concentrations of cerivastatin. Clin Pharmaol Ther 2002;72:685-691.

Barnes HJ, Arlotto MP, Waterman MR. Expression and enzymatic activity of recombinant cytohrome P450 17-alpha-hydroxylase in Esherichia coli. Proc Natl Acad Sci 1991;88:5597-5601.

Brown HS, Galetin A, Hallifax D, Houston B. Prediction of in vivo drug-drug interactions from in vivo data: factors affecting prototypic drug-drug interactions involving CYP2C9, CYP2D6 and CYP3A4. Clin Pharmacokinet 2006;45: 10351050.

Carlson AM, Morris LS. Coprescription of terfenadine and erythromycin or ketoconazole: an assessment of potential harm. J Am Pharm Assoc (Wash) 1996; NS36:263-269.

Capone D, Aiello C, Santoro GA, Gentile A, Stanziale P, D'Alessandro R, Imperatore $\mathrm{P}$, Basile V. Drug interaction between cyclosporine and two antimirobial agents, josamycin and rifampicin, in organ-transplanted patients. Int J Clin Pharmacol Res 1996;16:73-76.

Chiba M, Jin L, Neway W, Vacca JP, Tata JR, Chapman K, Lin JH. Drug Metab Disp 2001;29:1-3.

Crespi CL. Xenobiotic-metabolizing human cells as tools for pharmacological and toxicological research. Adv Drug Res 1995;26:179-235.

Diasio RB. Sorivudine and 5-fluorouracil; a clinically significant drug-drug interaction due to inhibition of dihydropyrimidine dehydrogenase. $\mathrm{Br} \mathrm{J}$ Clin Pharma Col 1998;46:1-4.

Donato MT, Jimenez N, Castell JV, Gomez-Lechon J. Fluorescence-based assays for screening nine cytochrome P450 (P450) activities in intact cells expressing individual human P450 enzymes. Drug Metab Disp 2004;32:699-706.

Emoto C, Murase S, Sawada Y, Jones BC, Iwasaki K. In vitro inhibitory effects of 1aminobenzotriazole on drug oxidations catalyzed by human cytochrome P450 enzymes: a comparison with SKF-525A and ketoconazole. Drug Metab Pharmacokinet 2003;18:287-295.

Friedberg T, Pritchard MP, Bandera M, Hanlon SP, Yao D, McLaughlin LA, Ding S, Burhell B, Wolf CR. Merits and limitations of recombinant models for the study of human P450-mediated drug metabolism and toxicity - an intralaboratory comparison. Drug Metab Rev 1999;31:523-544.

Guengerich FP. Cytochrome P450s and other enzymes in drug metabolism and toxicity. AAPS J 2006;8:E101-E111.

Hariparsad N, Nallani S, Sane RS, Buckley DJ, Buckley AR, Desai PB. Induction of CYP3A4 by efavirenz in primary human hepatocytes: comparison with rifampin and phenobarbital. J Clin Pharmaol 2004;44:1273-1281.

Henderson L, Yue QY, Berqquist C, Gerden B, Arlett P. St. John's Wort (Hypericum perforatum): drug interactions and clinical outcomes. $\mathrm{Br} \mathrm{J}$ Clin Pharmacol 2002;54:349-356.

Hewitt NJ, Lechon MJ, Houston JB, Hallifax D, Brown HS, Maurel P, Kenna JG, Gustavsson L, Lohmann C, Skonberg C, Huillouzo A, Tuschi G, Li AP, Elcluyse E, 
Groothuis GM, Hengstler JG. Primary hepatocytes: current understanding of the regulation of metabolic enzymes and transporter proteins, and pharmaceutical practice for the use of hepatocytes in metabolism, enzyme induction, transporter, clearance, and hepatoxicity studies. Drug Metab Rev 2007;39:159-234.

Huang SM, Lesko LJ, Williams RL. Assessment of the quality and quantity of drugdrug interaction studies in recent NDA submissions: study design and data analysis issues. J Clin Pharmacol 1999;39:1006-1014.

Kato M, Tachibana T, Ito K, Sugiyama Y. Evaluation of methods for predicting drugdrug interactions by Monte Carlo simulation. Drug Metab Pharmacokinet 2003;18:121-127.

Kim JY, Baek M, Lee S, Kim SO, Dong MS, Kim BR, Kim DH. Characterization of the selectivity and mechanism of cytochrome P450 inhibition by dimethyl-4,4'dimethoxy-5,6,5',6'-dimethylenedioxybiphenyl-2,2'-dicarboxylate. Drug Metab Disp 2001;29:1555-1560.

Li AP. Scientific basis of drug-drug interactions: mechanism and preclinical evaluation. Drug Inform J 1988;32:657-664.

Li AP. Primary hepatocyte cultures as an in vitro experimental model for the evaluation of pharmacokinetic drug-drug interactions. Adv Pharmacol 1997;43:103-130.

Li AP. Screening for human ADME/Tox drug properties in drug discovery. Drug Discov Today 2001;6:357-366.

Li AP. In vitro approaches to evaluate ADMET drug properties. Curr Top Med Chem 2004;4:701-706.

Li AP. Human hepatocytes: isolation, cryopreservation and applications in drug development. Chem Biol Interact 2007;168:16-29.

Li AP, Gorycki PD, Hengstler JG, Kedderis GL, Koebe HG, Rahmani R, de Sousas G, Silva JM, Skett P. Present status of the application of cryopreserved hepatocytes in the evaluation of xenobiotics: consensus of an international expert panel. Chem Biol Interact 1999a; 121:117-123.

Li AP, Hartman NR, Lu C, Collins JM, Strong JM. Effects of cytochrome P450 inducers on 17 alpha-ethinyloestradiol (EE2) conjugation by primary human hepatocytes. Br J Clin Pharmacol 1999;48:733-742.

Li AP, Lu C, Brent JA, Pham C, Fackett A, Ruegg CE, Silber PM. Cryopreserved human hepatocytes: characterization of drug-metabolizing enzyme activities and applications in higher throughput screening assays for hepatotoxicity, metabolic stability, and drug-drug interaction potential. Chem Biol Interact 1999b;121: 1735.

Li AP, Maurel P, Gomez-Lechon MJ, Cheng LC, Jurima-Romet M. Applications of primary human hepatocytes in the evaluation of P450 induction. Chem Biol Interact 1997; 107:5-16.

Li AP, Rasmussen A, Xu L, Kaminski DL. Rifampicin induction of lidocain metabolism in cultured human hepatocytes. J Pharmacol Exp Ther 1995;274: 673677.

Lillibridge JH, Liang BH, Kerr BM, Webber S, Quart B, Shetty BV, Lee CA. Characterization of the selectivity and mechanism of human cytochrome P450 inhibition by the human immunodeficiency virus-protease inhibitor nelfinavir mesylate. Drug Metab Disp 1998;26:609-616. 
Lu C, Miwa GT, Prakash SR, Gan LS, Balani SK. A novel model for the prediction of drug-drug interactions in humans based on in vitro cytochrome p450 phenotypic data, Drug Metab Disp 2007;35:79-85.

Lu AYH, Wang RW, Lin JH. Commentary: Cytochrome P450 in vitro reaction phenotyping: a re-evaluation of approaches for P450 isoform identification. Drug Metab Disp 2003;31:345-350.

MacGregor JT, Collins JM, Sugiyama Y, Tyson CA, Dean J, Smith L, Andersen M, Curren RD, Houston JB, Kadlubar FF, Kedderis GL, Krishnan K, Li AP, Parchment PE, Thummel K, Tomaszewski JE, Ulrich R, Vickers AE, Wrighton SA. In vitro human tissue models in risk assessment: report of a consensus-building workshop. Toxicol Sci 2001;59:17-36.

Madeira M, Levine M, Chang TKH, Mirfazaelian A, Bellward G. The effect of cimetidine on dexromethorphan $O$-demethylase activity of human liver microsomes and recombinant CYP2D6. Drug Metab Disp 2004;32:460-467.

McGinnity DF, Berry AJ, Kenny JR, Grime K, Riley RJ. Evaluation of time-dependent cytochrome P450 inhibition using cultured human hepatocytes. Drug Metab Disp 2006;34:1291-1300.

Nelson AC, Huang W, Moody DE. Human liver microsome preparation: impact on the kinetics of L- $\alpha$-acetylmethadol (LAAM) $N$-demethylation and dextromethorphan $O$ demethylation. Drug Metab Disp 2001;29:319-325.

Omar MA, Wilson JP. FDA adverse event reports on statin associated rhabdomyolysis. Ann Pharmacother 2002;36:288-295.

Ozdemir O, Boran M, Gokce V, Uzun Y, Kocak B, Korkmaz S. A case with severe rhabdomyolysis and renal failure associated with cerevastatin-gemfibrozil combination therapy-a case report. Angiology 2000;51:695-697.

Raucy J, Lasker JM. Isolation of P450 enzymes from human livers. Methods Enzymol 1991;206:577-594.

Renwick AB, Surry D, Price RJ, Lake BG, Evans DC. Metabolism of 7-benzyloxy-4trifluoromethylcoumarin by human hepatic cytochrome P450 isoforms. Xenobiotica 2004;30:955-969.

Ring BJ, Gillespie JS, Eckstein JA, Wrighton SA. Identification of human cytochromes P450 responsible for atomozetine metabolism. Drug Metab Disp 2002;30:319-323.

Rodrigues AD. Integrated cytochrome P450 reaction phenotyping: attempting to bridge the gap between cDNA-expressed cytochromes P450 and native human liver microsomes. Biochem Pharmacol 1999;57:465-480.

Roymans D, Annaert P, Van Houdt J, Weygers A, Noukens J, Sensenhauser C, Silva J, van Looveren C, Hendrickx J, Mannens G, Meuldermans W. Expression and induction potential of cytohromes P450 in human cryopreserved hepatocytes. Drug Metab Disp 2005;33:1004-1016.

Roymans D, Van Looveren C, Leone A, Parker JB, McMillan M, Johnson MD, Koganti A, Gilissen R, Silber P, Mannens G, Meuldermans W. Determination of cytochrome P450 1A2 and P450 3A4 induction in cryopreserved human hepatocytes. Biochem Pharmacol 2004;67:427-437.

Schalcher C, Schad K, Brunner-La Rocca HP, Schindler R, Oechslin E, Scharf C, Suetsch G, Bertel O, Kiowski W. Interaction of sildenafil with cAMP-mediated vasodilation in vivo. Hypertension 2002;40:763-767. 
Uttamsingh V, Lu C, Miwa G, Gan LS. Relative contributions of the five major human cytochromes P450, 1A2, 2C9, 2C19, 2D6, and 3A4, to the hepatic metabolism of the proteasome inhibitor bortezomib. Drug Metab Disp 2005;33:1723-1728.

Vazquez E, Whitfield L. Seldane warnings. Posit Aware 1997;8:12.

Vickers AE, Sinclair JR, Zollinger M, Heitz F, Glanzel U, Johanson L, Fischer V. Multiple cytochrome P450s involved in the metabolism of terbinafine suggest a limited potential for drug-drug interactions. Drug Metab Dispos 1999;27: 10291038.

Von Moltke LL, Greenblatt DJ, Duan SX, Harmatz JS, Wright CE, Shader RI. Inhibition of terfenadine metabolism in vitro by azole antifungal agents and by selective serotonin reuptake inhibitor antidepressants: relations to pharmacokinetic interactions in vivo. J Clin Psychopharmacol 1996;16:104-112.

Vrtic F, Haefeli WE, Drewe J, Krahenbuhl S, Wenk M. Interaction of ibuprofen and probenecid with metabolizing enzyme phenotyping procedures using caffeine as the probe drug. Br J Clin Pharmacol 2003;55:191-198.

Walsh CT. Suicide substrates, mechanism-based enzyme inactivators: recent developments. Ann Rev Biochem 1984;53:493-535.

Wang RW, Newton DJ, Liu N, Atkins WM, Lu AYH. Human cytochrome P-450 3A4: in vitro drug-drug interaction patterns are substrate-dependent. Drug Metab Disp 2000;28:360-366.

Wen X, Wang JS, Backman JT, Kivisto KT, Neuvonen PJ. Gemfibrozil as an inhibitor of human cytochrome P450 2C9. Drug Metab Disp 2001;29:1359-1361.

Zhang H, Cui D, Wang B, Han YH, Balimane P, Yang Z, Sinz M, Rodriqus AD. Pharmacokinetic drug interactions involving 17alpha-ethinylestradiol: a new look at an old drug. Clin Pharmacokinet 2007;46:133-157. 
